\title{
Current Surgical Management of Colorectal Cancer Liver Metastases: A Mini Review
}

\author{
Theodoros E Pavlidis ${ }^{\mathrm{a}, \mathrm{b}}$, Nikolaos G Symeonidis ${ }^{\mathrm{a}}$, Kyriakos Psarras ${ }^{\mathrm{a}}$, \\ Efstathios T Pavlidis ${ }^{\text {a }}$, Athanasios K Sakantamis ${ }^{\text {a }}$
}

\begin{abstract}
Colorectal cancer is responsible for $10 \%$ of cancer related deaths and is the third most common cancer type in men and the second in women. Metastatic disease will develop in nearly $60 \%$ of patients with colorectal cancer, half of which will be located in the liver. At least $30 \%$ of the patients who underwent potentially curative primary tumor resection have liver micrometastases. A PubMed search of relevant articles published up to 2011 was performed to identify current information about colorectal liver metastases regarding diagnosis and management with emphasis to surgery. The results shows that hepatectomy is the only potentially curative option resulting in 5-year survival for one third of the patients, but only 10 - $30 \%$ of the patients are suitable for a radical procedure. Indications include ability to resect the tumor without residual disease, with removal of at least $1 \mathrm{~cm}$ of healthy tissue and clear margins, and the absence of extrahepatic metastatic disease. Specialized centers achieve mortality rate less than $5 \%$ and morbidity $20-50 \%$. 5 -year survival following hepatic resection is $25-40 \%$ with mean survival of 28 - 40 months. We conclude that current management of colorectal cancer liver metastases requires a multidisciplinary approach. Operative strategies and novel techniques that achieve wider excision areas with minimal blood loss make hepatectomy safe and effective.
\end{abstract}

Keywords: Advanced colorectal cancer; Liver metastases; Hepatic metastasis; Hepatectomy; Surgical management; Curative resection

Manuscript accepted for publication November 10, 2011

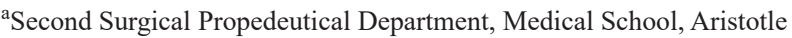
University of Thessaloniki, Hippocration Hospital, Konstantinoupoleos 49, 54642 Thessaloniki, Greece

${ }^{\mathrm{b}}$ Corresponding author: Theodoros E Pavlidis, A Samothraki 23, 54248

Thessaloniki, Greece. Email: pavlidth@med.auth.gr
}

doi:10.4021/jcs106e

\section{Introduction}

Colorectal cancer, which is the third most common cancer type in men and the second in women, appears with increasing frequency and is responsible for approximately $10 \%$ of cancer-related deaths. $60 \%$ of colorectal cancer patients will develop metastatic disease, half of which will be located in the liver. While the lung is the most common extra-abdominal metastatic site, other less frequent metastatic locations such as the brain, bones, ovaries, penis and adrenal glands have been reported [1-3]. A multidisciplinary approach using of all modalities improves the short and long-term outcome [4-7].

\section{Hepatic metastases}

Early diagnosis of liver metastases from colorectal cancer is very important for effective treatment. A proteomic analysis of differentially expressed proteins, which were closely related to such metastasis, has been recently introduced. The elevation of arginase has been proposed as an early molecular marker of predictive value [8]. FasL gene expression has also been proposed as a marker of aggressive biological behavior that facilitates liver metastasis and indicates resistance to chemotherapy [9]. The level of cell membrane phospholipids and protein kinase $\mathrm{C}$ isoenzyme expression has been used as another molecular marker [10]. At least $30 \%$ of the patients who underwent potentially curative resection of the primary tumor have liver micrometastases. Prompt diagnosis during the course of the postoperative follow-up is essential for effective treatment. The patients should be followed-up every 3 - 6 months for the first 3 years and once every year thereafter. It is recommended that tumor marker CEA should be monitored in a very defined population, especially when elevated levels are found preoperatively and could be valuable in early recognition of metastases [1].

Ultrasonography (US), computerized tomography (CT, CT portogram) and magnetic resonance imaging (MRI) aid diagnosis and hepatic metastasis staging. Full-body fluorodeoxyglucose positron emission tomography (FDG-PET) is currently used for the staging of hepatic metastases and is 
based on the fact that cancer cells utilize more glucose than normal cells. It is an essential study in staging for more intrahepatic, portal nodal, distant nodal and extrahepatic disease. FDG-PET can provide a helpful adjunct to CT in detecting extrahepatic metastases and also in making classic staging more accurate. Nevertheless, it does not seem to provide further information for the determination of the extent of metastatic disease in the liver parenchyma [1]. It has been reported that FDG-PET added further diagnostic value by $38 \%$ reduction in futile laparotomies [11]. Integrated PET/ CT is another novel diagnostic modality currently available in better preoperative staging and restaging during followup after curative resection. Although, its exact clinical value and efficacy has not defined yet, it is related with promising results [12].

Although hepatic resection is the only potentially curative option resulting in 5-year survival for one third of the patients, only $10-30 \%$ of the patients are suitable for a radical procedure [3, 13-15]. Current treatment strategies such as down-staging chemotherapy, portal vein embolization and two-stage resections can be applied in cases of extensive metastases and result in further increasing the resectability rate by $15 \%[1,16,17]$. The aim of down-staging chemotherapy is to reduce the size of the metastases as much as possible before resection. Two-stage resection is based on the fact that the first, more limited resection triggers the regenerative capability and compensatory hyperplasia of liver cells in order to prevent functional insufficiency of the remaining liver. The second, more radical resection is intended to remove all metastatic disease. Two-stage hepatectomy for extensive bilateral metastases is performed with acceptable morbidity and mortality, but the second stage is not possible in $20-25 \%$ of the patients [18]. Portal vein embolization is mainly used for the treatment of hepatocellular carcinoma and cholangiocarcinoma, but also it is indicated in a colorectal metastatic disease. This technique is based on the regenerative capacity of the liver and is used prior to a major hepatic resection in order to provoke compensatory hypertrophy and increased functional ability (up to 20\%) of the remaining liver. Embolic agents commonly used are acrylic microspheres, polyvinyl alcohol particles or microcoils. This technique is not devoid of complications, but very rare, (hemoperitoneum, hemobilia) and can also be the cause of metastatic loci formation in the other lobe $[3,13]$.

Consequently, neoadjuvant chemotherapy or biologic therapies for unresectable colorectal hepatic metastasis may be useful in certain patients by improving the resection rate [19].

Recent results with the biological agent bevacizumab, a humanized monoclonal antibody against VEGF (vascular endothelial growth factor) receptor and cetuximab, a humanized monoclonal antibody against EGF (epidermal growth factor) receptor have showed improved outcome in advanced colorectal cancer, when added to current first line chemotherapy $[20,21]$

It has recently been reported that the use of yttrium-90 microspheres and concomitant FOLFOX chemotherapy is successful neoadjuvant management [22]. However, this preoperative management cannot substitute surgery. Even, the full response to neoadjuvant chemotherapy, by complete disappearing on imaging of colorectal liver metastases, indicates still subsequent operative exploration and direct assessment for resection of any otherwise not apparent residual lesion [23, 24].

Intraoperative findings such as peritoneal seeding and small superficial hepatic lesions undetected during the preoperative diagnostic workup may alter the operative plan and obviate the need for hepatic resection. Staging laparoscopy combined with laparoscopic ultrasound may prevent an unnecessary laparotomy [25]. Unfortunately, in cases of metachronous metastases, considerable difficulties can be encountered during laparoscopy due to postoperative adhesions caused by prior primary tumor resection [13].

\section{Indications for hepatectomy}

Hepatectomy is indicated firstly when tumor resection without residual disease is possible, with removal of at least 1 $\mathrm{cm}$ of healthy tissue and clear margins and secondly, when no extrahepatic metastatic disease is present $[13,26]$. The speculation that a $1 \mathrm{~cm}$ margin is required for a successful outcome is a common practice, although some authors would argue that ability to obtain any negative margin is an indication regardless of size of the margin. Pulmonary metastasis with diaphragm infiltration is an exception to the above, noted that en-bloc resection can be achieved. Failure to meet the above conditions equals to absolute contra-indication for a major hepatectomy. However, in some cases the resection of liver metastases with extrahepatic disease has been attempted [27].

Risk factors for recurrence after hepatic resection and therefore relative contra-indications are the following: hepatic metastasis synchronous with the primary tumor, multiple metastases (3 or more) and metastatic tumor size ( $>5$ $\mathrm{cm})$, presence of satellite nodules, tumor occupying more than $50 \%$ of liver parenchyma, elevated CEA level (> $30 \mathrm{ng} /$ $\mathrm{ml}$ ), intraoperative blood transfusion ( $>2$ units), infiltrated hilar lymph nodes, disease-free interval from primary tumor resection until hepatic metastasis detection less than 12 months [13].

\section{Hepatic resection outcome}

Mortality following major hepatectomy is less than $5 \%$ in specialized centers and morbidity ranges between $20-50 \%$ [1]. 5-year survival after hepatectomy ranges between 25 $40 \%$ and the mean survival between 28 - 40 months. Few studies report 10-year survival which ranges between 20 - 
$26 \%$. Additional resection in patients who have already had a hepatectomy is possible with even similar 5-year survival, approximately $30 \%$ [1].

Improved survival after hepatectomy over the time can be attributed to better diagnosis, operative management and chemotherapy [28]. Overall 5-year survival up to $60 \%$ has been reported [3].

A recent large population-based study from the UK has found a consistently increasing rate of hepatic resection for colorectal cancer metastases; also, a crude 5-year survival after hepatectomy $44.2 \%$, which is comparable to that of $42.2 \%$ in stage III colorectal cancer patients [29].

It has been reported that alternating systemic oxaliplatin and capecitabine with hepatic artery infusion of floxuridine for resected liver metastases showed more than 85\% 2-year survival, it is well-tolerated [30].

In contrast with the above encouraging post-hepatectomy results, hepatic metastases left untreated result in mean survival of 5 - 10 months while 5-year survival after palliative treatment is exceptionally rare [1].

\section{Synchronous hepatic metastases and optimal hepatec- tomy time}

Operative strategy for hepatic metastases discovered at the same time with the primary tumor remains controversial. Although proponents of the staged approach (2 - 3 months delay between resections) claim that the simultaneous resection strategy has less favorable short-term outcome, there is a growing number of studies supporting the combined latter approach [31]. Combined colonic and hepatic resection is safe and more effective than delayed (6 months at the latest) hepatectomy and is the optimal choice in selected patients and in specialized centers $[32,33]$. Primary resection of synchronous liver metastases demands careful patient selection and institutional experience [34]. Major hepatectomies for synchronous colorectal cancer have similar short-term results compared to the staged approach, even in rectal cancer cases in which pelvic anatomy poses additional difficulties [34-36]. However, while in synchronous liver metastases some consider appropriate leaving a three-month interval for hepatic resection, this is of no clinical benefit in metachronous liver metastases [37]. Preoperative chemotherapy does not improve the outcome in patients with solitary liver metastasis, in contrast with postoperative chemotherapy, which is associated with better results, especially in tumor diameter $>5 \mathrm{~cm}$ [38]. Nevertheless, in synchronous colorectal liver metastases, a reverse "liver first" approach has been shown feasible and safe [39].

Contraindications for the simultaneous resection approach are the poor general health $(\mathrm{ASA}>3)$, colonic obstruction and/or perforation and the inability to completely remove all cancerous tissue. Most surgeons recommend that during the simultaneous resection the colorectal resection should be performed first and the hepatectomy should follow, but there is controversy over this order [36].

Hepatic metastasis is characterized as synchronous if it is diagnosed before colorectal surgery or even during laparotomy. Although the presence of synchronous hepatic metastasis is considered as a negative prognostic factor, it does not constitute a contraindication for hepatectomy provided that it can be completely removed without residual disease. In these cases, the 5-year survival is $20-40 \%$ [31].

Low anterior resection exhibits increased operative difficulties and elevated risk of anastomotic dehiscence, but is not contraindicated for concurrent major hepatectomy. When vascular occlusion is performed during hepatectomy, the occluded portal vein causes a transient portal hypertension and consequent intestinal wall edema which is considered as an aggravating factor to the healing of the colonic anastomosis. Low-lying anastomoses are in even greater danger due to impaired blood supply [31, 40].

In addition to the previously already mentioned factors, five preoperative prognostic risk factors for recurrence after hepatectomy have been introduced by the New York Memorial Sloan-Kettering Cancer Center: disease-free interval < 12 months, CEA > 200, positive lymph nodes near the primary tumor, more than one hepatic metastases and size of the hepatic lesion $>5 \mathrm{~cm} \mathrm{[35].}$

\section{Hepatectomy technique}

Surgical resection aims at the removal of all metastatic disease from the liver while preserving sufficient parenchyma with adequate blood supply (portal and arterial), venous return and biliary drainage [13]. Resection is typically performed on the boundaries of the 8 segments in which the liver is divided according to the Couinaud classification. Hepatectomy is considered as major when 3 or more segments are resected; while it is considered as extended when 5 or more segments are resected. However, hepatectomy is not limited to segmental or lobar approaches. Most hepatic surgeons perform the safest resection to achieve a negative margin and preserve a maximum of hepatic tissue. Hepatic dysfunction can be assessed by various biochemical and clinical measurements, and should be suspected when both prothrombin time is persistently $>50 \%$ and total bilirubin is $>5 \mathrm{mg} / \mathrm{dl}$ on the 4 th postoperative day [31].

The basic operative steps in hepatectomy commence with a bilateral subcostal incision (with vertical midline extension) or another preferable incision, thorough inspection of the peritoneal cavity in order to exclude peritoneal seeding or pelvic dissemination, followed by extensive hepatic mobilization. Bimanual palpation and intraoperative ultrasonogram must be performed routinely, hilar structures (hepatic artery, portal vein, hepatic duct) and hepatic veins are dissected and appropriate branches are ligated depending on the type of resection. In non-lobar/sectionectomy cases can be 
often done a Pringle maneuver and customized parenchymal division and intrahepatic major vessel and biliary ligation. Hepatic parenchyma is transected along the planned line of resection and hemorrhage from the cut margin is controlled by suture ligation or other hemostatic agents.

Many different techniques have been applied for the safe transection of the hepatic parenchyma such as complete vascular occlusion, finger fracture and more recently various contact or thermal methods [13]. The latter include cavitational ultrasonic aspirator (CUSA), microwave tissue coagulation device, water jet injection (accused for cancer cell seeding), bipolar ligasure sealing device, Habib 4 electrode method with radiofrequencies, Ultracision Harmonic scalpel and various stapling devices.

The recent advent of modern laparoscopic techniques resulted in achieving laparoscopic hepatectomy with good outcome in selected patients despite the increased cost [13]. The current world position on laparoscopic liver surgery includes liver resection for solitary lesions, $5 \mathrm{~cm}$ or less, located in segments 2 to 6. Major hepatectomies (left or right) require a lot of such experience. There is not an adverse effect of laparoscopic resection on oncological outcome [41]. Comparing oncologic results of laparoscopic versus open hepatectomy for colorectal liver metastases in a highly specialized center showed equivalent results in selected patients [42]. In solitary lesions, laparoscopic radiofrequency thermal ablation can be an alternative to resection in patients who in otherwise are excluded from resection [43]. Patients with smaller than $3 \mathrm{~cm}$ lesions are candidates for RFA with equivalent outcome. Previous reports of poor control and shorter survival with RFA described in patients with unresectable disease and not comparable to RFA done with curative intent.

\section{Palliative treatment of hepatic metastases}

Current anatomic staging strategies with specific molecular markers refine the indication for targeted therapy [44]. As mentioned above the optimal management of metastatic colorectal cancer is the resection of both primary and hepatic lesions. In case of extensive metastatic liver involvement from rectal cancer, current chemotherapy, FOLFOX and FOLFIRI, improves resection rate and survival, although there are not well designed studies that examine the conversion rates from unresectable to resectable for initially unresectable disease. The question that now has been raised is whether there is survival benefit from primary rectal resection in unresectable liver metastasis. The answer of course is no, but the primary resection is justified only for palliative reasons and local control [45]. With this improvement in chemotherapy and neoadjuvant chemoradiation, the decision for primary tumor resection in patients with advanced IV stage colorectal cancer should be individualized. Although, it is favorable in many cases, in patients with a poor performance status, extensive hepatic metastasis and extensive lymph node involvement, a nonsurgical approach is preferable [46].

Chemotherapy is frequently used for palliative treatment of hepatic metastases and can be systemic or local intraarterial. Intraarterial chemotherapy is performed with an infusion pump and requires insertion of a catheter in the hepatic artery, which is introduced through the gastroduodenal artery after its peripheral segment has been ligated. Operative insertion of the catheter should also include cholecystectomy in order to prevent acute gallbladder wall necrosis. Other palliative modalities include chemoembolization, in which hepatic artery infusion with Irinotecan loaded beads is used, local ablative techniques such as radiofrequency ablation, laser thermal ablation and cryoablation and other experimental procedures (microwaves, electrolysis) [1, 47-49].

\section{Conclusions}

In conclusion, optimal management of colorectal cancer liver metastases requires a multidisciplinary approach. Early diagnosis, accurate staging and determination of resectability are of great value for treatment planning. Operative strategies and novel techniques that achieve wider excision areas with minimal blood loss make hepatectomy safer and more effective. As result of this combined effort, better outcome is achieved, especially in specialized centers. Increased survival and good quality of life after resection of colorectal cancer hepatic metastases is the focus of current research.

\section{Funding}

None.

\section{Ethical Approval}

Not needed.

\section{Competing Interest}

No benefits in any form have been received or will be received from a commercial party related directly or indirectly to the subject of this article.

\section{References}

1. Fusai G, Davidson BR. Management of colorectal liver metastases. Colorectal Dis. 2003;5(1):2-23.

2. Mohammad WM, Balaa FK. Surgical management of colorectal liver metastases. Clin Colon Rectal Surg. 
2009;22(4):225-232.

3. Sharma S, Camci C, Jabbour N. Management of hepatic metastasis from colorectal cancers: an update. J Hepatobiliary Pancreat Surg. 2008;15(6):570-580.

4. Gallagher DJ, Kemeny N. Metastatic colorectal cancer: from improved survival to potential cure. Oncology. 2010;78(3-4):237-248.

5. Kemeny N. The management of resectable and unresectable liver metastases from colorectal cancer. Curr Opin Oncol. 2010;22(4):364-373.

6. Wagman LD, Byun TE. Managing colorectal cancer liver metastases. Oncology (Williston Park). 2009;23(12):1063-1071.

7. Abdel-Misih SR, Schmidt CR, Bloomston PM. Update and review of the multidisciplinary management of stage IV colorectal cancer with liver metastases. World J Surg Oncol. 2009;7:72.

8. Li SY, An P, Cai HY, Bai X, Zhang YN, Yu B, Zuo FY, et al. Proteomic analysis of differentially expressed proteins involving in liver metastasis of human colorectal carcinoma. Hepatobiliary Pancreat Dis Int. 2010;9(2):149-153.

9. Li SY, Yu B, An P, Wei JC, Zuo FY, Cai HY. Influence of FasL gene expression on hepatic metastasis of colorectal carcinoma. Hepatobiliary Pancreat Dis Int. 2004;3(2):226-229.

10. Li SY, Yu B, An P, Liang ZJ, Yuan SJ, Cai HY. Effects of cell membrane phospholipid level and protein kinase $\mathrm{C}$ isoenzyme expression on hepatic metastasis of colorectal carcinoma. Hepatobiliary Pancreat Dis Int. 2004;3(3):411-416.

11. Wiering B, Adang EM, van der Sijp JR, Roumen RM, de Jong KP, Comans EF, Pruim J, et al. Added value of positron emission tomography imaging in the surgical treatment of colorectal liver metastases. Nucl Med Commun. 2010;31(11):938-944.

12. Wiering B, Vogel WV, Ruers TJ, Oyen WJ. Controversies in the management of colorectal liver metastases: role of PET and PET/CT. Dig Surg. 2008;25(6):413420.

13. Lochan R, White SA, Manas DM. Liver resection for colorectal liver metastasis. Surg Oncol. 2007;16(1):3345.

14. Benzoni E, Lorenzin D, Baccarani U, Adani GL, Favero A, Cojutti A, Bresadola F, et al. Resective surgery for liver tumor: a multivariate analysis of causes and risk factors linked to postoperative complications. Hepatobiliary Pancreat Dis Int. 2006;5(4):526-533.

15. Primrose JN. Surgery for colorectal liver metastases. Br J Cancer. 2010;102(9):1313-1318.

16. Jaeck D, Oussoultzoglou E, Rosso E, Greget M, Weber $\mathrm{JC}$, Bachellier P. A two-stage hepatectomy procedure combined with portal vein embolization to achieve curative resection for initially unresectable multiple and bilobar colorectal liver metastases. Ann Surg. 2004;240(6):1037-1049; discussion 1049-1051.

17. Shimada H, Tanaka K, Matsuo K, Togo S. Treatment for multiple bilobar liver metastases of colorectal cancer. Langenbecks Arch Surg. 2006;391(2):130-142.

18. Tsai S, Marques HP, de Jong MC, Mira P, Ribeiro V, Choti MA, Schulick RD, et al. Two-stage strategy for patients with extensive bilateral colorectal liver metastases. HPB (Oxford). 2010;12(4):262-269.

19. Davies JM, Goldberg RM. Optimum chemotherapy regimens for neoadjuvant therapy of hepatic colorectal metastases. J Surg Oncol. 2010;102(8):946-954.

20. Barugel ME, Vargas C, Krygier Waltier G. Metastatic colorectal cancer: recent advances in its clinical management. Expert Rev Anticancer Ther. 2009;9(12):18291847.

21. McWilliams RR, Erlichman C. Novel therapeutics in colorectal cancer. Dis Colon Rectum. 2005;48(8):16321650 .

22. Chua TC, Bester L, Akther J, Morris DL. Successful right hepatectomy after four treatments of yttrium-90 microspheres (SIR-Spheres) and concomitant FOLFOX as bridging therapy to resection of colorectal liver metastases. Anticancer Res. 2010;30(7):3005-3007.

23. Carpenter S, Fong Y. Management of disappearing colorectal hepatic metastases. Adv Surg. 2010;44:269279.

24. Thomay AA, Charpentier KP. Optimizing resection for "responding" hepatic metastases after neoadjuvant chemotherapy. J Surg Oncol. 2010;102(8):1002-1008.

25. Shah AJ, Phull J, Finch-Jones MD. Clinical risk score can be used to select patients for staging laparoscopy and laparoscopic ultrasound for colorectal liver metastases. World J Surg. 2010;34(9):2141-2145.

26. Mayo SC, Pawlik TM. Current management of colorectal hepatic metastasis. Expert Rev Gastroenterol Hepatol. 2009;3(2):131-144.

27. de Haas RJ, Wicherts DA, Adam R. Resection of colorectal liver metastases with extrahepatic disease. Dig Surg. 2008;25(6):461-466.

28. House MG, Ito H, Gonen M, Fong Y, Allen PJ, DeMatteo RP, Brennan MF, et al. Survival after hepatic resection for metastatic colorectal cancer: trends in outcomes for 1,600 patients during two decades at a single institution. J Am Coll Surg. 2010;210(5):744-752, 752-745.

29. Morris EJ, Forman D, Thomas JD, Quirke P, Taylor EF, Fairley L, Cottier B, et al. Surgical management and outcomes of colorectal cancer liver metastases. Br J Surg. 2010;97(7):1110-1118.

30. Alberts SR, Roh MS, Mahoney MR, O'Connell MJ, Nagorney DM, Wagman L, Smyrk TC, et al. Alternating systemic and hepatic artery infusion therapy for resected liver metastases from colorectal cancer: a North Central Cancer Treatment Group (NCCTG)/ National 
Surgical Adjuvant Breast and Bowel Project (NSABP) phase II intergroup trial, N9945/CI-66. J Clin Oncol. 2010;28(5):853-858.

31. Capussotti L, Ferrero A, Vigano L, Ribero D, Lo Tesoriere R, Polastri R. Major liver resections synchronous with colorectal surgery. Ann Surg Oncol. 2007; 14(1):195-201.

32. Chua HK, Sondenaa K, Tsiotos GG, Larson DR, Wolff BG, Nagorney DM. Concurrent vs. staged colectomy and hepatectomy for primary colorectal cancer with synchronous hepatic metastases. Dis Colon Rectum. 2004;47(8):1310-1316.

33. Moug SJ, Smith D, Leen E, Roxburgh C, Horgan PG. Evidence for a synchronous operative approach in the treatment of colorectal cancer with hepatic metastases: a case matched study. Eur J Surg Oncol. 2010;36(4):365-370.

34. Tan EK, Ooi LL. Colorectal cancer liver metastases understanding the differences in the management of synchronous and metachronous disease. Ann Acad Med Singapore. 2010;39(9):719-715.

35. Martin R, Paty P, Fong Y, Grace A, Cohen A, DeMatteo $\mathrm{R}$, Jarnagin $\mathrm{W}$, et al. Simultaneous liver and colorectal resections are safe for synchronous colorectal liver metastasis. J Am Coll Surg. 2003;197(2):233-241; discussion 241-232.

36. Vassiliou I, Arkadopoulos N, Theodosopoulos T, Fragulidis G, Marinis A, Kondi-Paphiti A, Samanides L, et al. Surgical approaches of resectable synchronous colorectal liver metastases: timing considerations. World J Gastroenterol. 2007;13(9):1431-1434.

37. Ueno S, Sakoda M, Kitazono M, Iino S, Kurahara H, Minami K, Ando K, et al. Is delayed liver resection appropriate for patients with metachronous colorectal metastases? Ann Surg Oncol. 2011;18(4):1104-1109.

38. Adam R, Bhangui P, Poston G, Mirza D, Nuzzo G, Barroso $\mathrm{E}$, Ijzermans $\mathrm{J}$, et al. Is perioperative chemotherapy useful for solitary, metachronous, colorectal liver metastases? Ann Surg. 2010;252(5):774-787.

39. Mentha G, Roth AD, Terraz S, Giostra E, Gervaz P, Andres A, Morel P, et al. 'Liver first' approach in the treatment of colorectal cancer with synchronous liver metas- tases. Dig Surg. 2008;25(6):430-435.

40. Kusunoki M, Inoue Y. Current surgical management of rectal cancer. Dig Surg. 2007;24(2):115-119.

41. Buell JF, Cherqui D, Geller DA, O’Rourke N, Iannitti D, Dagher I, Koffron AJ, et al. The international position on laparoscopic liver surgery: The Louisville Statement, 2008. Ann Surg. 2009;250(5):825-830.

42. Castaing D, Vibert E, Ricca L, Azoulay D, Adam R, Gayet B. Oncologic results of laparoscopic versus open hepatectomy for colorectal liver metastases in two specialized centers. Ann Surg. 2009;250(5):849-855.

43. Berber E, Tsinberg M, Tellioglu G, Simpfendorfer CH, Siperstein AE. Resection versus laparoscopic radiofrequency thermal ablation of solitary colorectal liver metastasis. J Gastrointest Surg. 2008;12(11):1967-1972.

44. Greene FL. Staging of colon and rectal cancer: from endoscopy to molecular markers. Surg Endosc. 2006;20 Suppl 2:S475-478.

45. Cellini C, Hunt SR, Fleshman JW, Birnbaum EH, Bierhals AJ, Mutch MG. Stage IV rectal cancer with liver metastases: is there a benefit to resection of the primary tumor? World J Surg. 2010;34(5):1102-1108.

46. Stillwell AP, Ho YH, Veitch C. Systematic review of prognostic factors related to overall survival in patients with stage IV colorectal cancer and unresectable metastases. World J Surg. 2011;35(3):684-692.

47. Abdalla EK, Vauthey JN, Ellis LM, Ellis V, Pollock R, Broglio KR, Hess K, et al. Recurrence and outcomes following hepatic resection, radiofrequency ablation, and combined resection/ablation for colorectal liver metastases. Ann Surg. 2004;239(6):818-825; discussion 825817.

48. Wolpin BM, Meyerhardt JA, Mamon HJ, Mayer RJ. Adjuvant treatment of colorectal cancer. CA Cancer J Clin. 2007;57(3):168-185.

49. Martin RC, Robbins K, Tomalty D, O’Hara R, Bosnjakovic P, Padr R, Rocek M, et al. Transarterial chemoembolisation (TACE) using irinotecan-loaded beads for the treatment of unresectable metastases to the liver in patients with colorectal cancer: an interim report. World J Surg Oncol. 2009;7:80. 